\title{
Evaluation of the Effect of Micro-osteoperforations versus Piezopuncture on the Rate of Orthodontic Tooth Movement Associated with Canine Retraction
}

\author{
Tarek Farag ${ }^{1 *}$ (D), Wael Mohamed Mubarak Refai ${ }^{2}$, Ahmed Nasef $^{2}$, Omnia A. Elhiny $^{1}$, Ahmed Sh. Hashem ${ }^{2}$ \\ ${ }^{1}$ Department of Orthodontics and Pediatric Dentistry, National Research Centre, Cairo, Egypt; ${ }^{2}$ Department of Orthodontic, \\ Faculty of Dentistry, Minia University, Minya, Egypt
}

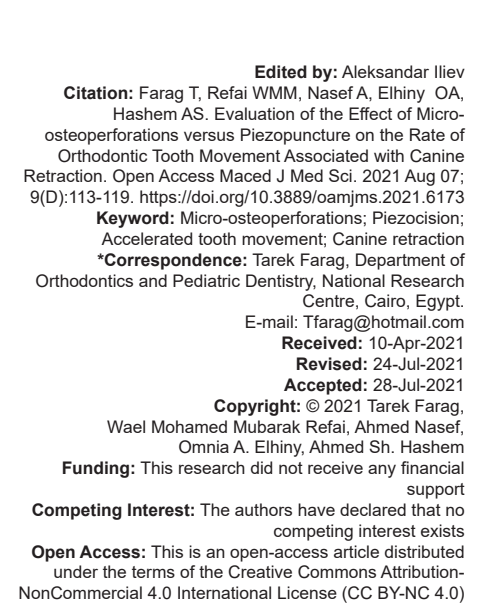

Abstract

AIM: The aim of the study was to investigate the effectiveness of using micro-osteoperforations (MOPs) or piezocision in accelerating tooth movement, during canine retraction, compared to standard canine retraction.

PATIENTS AND METHODS: A split-mouth study design was carried out with two Groups A and B. Each group contained 10 patients; in each patient, one side was used as a control side and the contralateral side received either MOPs (Group A) or piezocision (Group B). The assessment data were collected by direct intraoral measurements, every 2 weeks, over a 3 months retraction period.

RESULTS: Independent t-test, paired t-test, and ANOVA were used to analyze the results. In Group A, there was a statistically significant difference between the study and control sides $(p<0.001)$ with a total of $4.2 \pm 0.5 \mathrm{~mm}$ canine retraction in the MOPs assisted canine retraction side versus a $2.8 \pm 0.2 \mathrm{~mm}$ total canine retraction in the contro side. For Group B, there was a statistically significant difference between the study and control sides $(p<0.001)$ with a total of $3.6 \pm 0.4 \mathrm{~mm}$ canine retraction in the piezocision-assisted canine retraction side versus a $2.8 \pm 0.2 \mathrm{~mm}$ total canine retraction in the control.

CONCLUSION: MOPs and piezocision techniques accelerated the rate of canine retraction during orthodontic treatment, with the MOPs being slightly more effective.

\section{Introduction}

The average orthodontic treatment usually necessitates an extended duration of about 20-30 months [1]. The longer the treatment duration, the higher the risk of external root resorption [2], caries, white lesions [3], as well as decreased patient satisfaction and compliance [4]. The effectiveness of non-conventional methods for accelerating orthodontic tooth movement and shortening the duration of orthodontic treatment had become the key question for many researchers [5]. A variety of methods based on the biology of tooth movement was suggested such as pharmacological methods using Vitamin D [6], prostaglandin [7], interleukins [8], leukotrienes[9],orplatelet-richplasma[10].Physicalmethods were also employed (low-level laser therapy [11], electric current [12], electromagnetic field [13], and low-intensity pulsed ultrasound [14]) and surgical methods such as corticotomy [15], [16], micro-osteoperforations (MOPs) [17], [18], and piezocision [19], [20]. Surgical corticotomy is one popular and commonly used method to accelerate orthodontic tooth movement, control anchorage, and enhance molar intrusion and distalization [21]. It enhanced the regional acceleratory phenomenon (RAP) which has the main effect in accelerating OTM [22], [23]. Different surgical corticotomy methods were investigated by many researchers [24], [25], the main drawback was that it is an invasive technique which may cause undesirable side effects such as pain, swelling, and post-operative bleeding, and may negatively affect patients' quality of life [26]. For that reason, other less invasive surgical techniques were introduced to minimize these side effects such as MOPs and piezoelectric surgery (piezocision). MOPs are a procedure in which small pinhole perforations are created in the bone around the teeth to accelerate the rate of tooth movement during orthodontic treatment [27]. This procedure activates the release of cytokines that, in turn, recruit osteoclasts to the area to increase the rate of bone resorption, and does not require a prolonged execution time or any advanced training. On the other hand, piezocision [28] is a technique used for corticotomy [29] carried out by modulated ultrasonic frequency that permits highly precise and safe cutting of hard tissues. 
Accordingly, the aim of our study was to investigate the effectiveness of using MOPs or piezocision in accelerating tooth movement, during canine retraction, compared to standard canine retraction.

\section{Patients and Methods}

Twenty female and male patients with an age range from 15 to 25 years were enrolled in this study. They were recruited from the Outpatient Clinic at the Department of Orthodontics, Faculty of Dentistry, Minia University. The inclusion criteria were healthy general medical condition, healthy periodontal condition, full unit Class II canine relation, severe crowding, and/ or protrusion that required extraction of the maxillary first premolars followed by canine retraction, normal shape and structure of maxillary canines, no history of fillings or root canal treatment, and normal shape and structure of maxillary first molars. The study aim and detailed procedure were explained to the patients and/ or guardians along with the potential side effects and informed consents were signed. All safety precautions were followed during perforations and piezocision.

Pre-orthodontic records were taken for all the patients and analyzed (study casts, digital extraoral and intraoral photographs, and panoramic and lateral cephalometric radiographs). The sample was randomly divided into two groups, each contained 10 patients. A split-mouth study design was employed for each patient; in which one side served as control while the contralateral side was the study side. Assignment of patients and the choice of the side of intervention were done through a computer-generated randomization technique (www.random.org). In Group A: MOPs assessment was performed on the study side. In Group B: Piezocision assessment was performed on the study side.

First, the subjects were referred to an oral surgeon to extract the first premolars without squeezing of the socket. A healing interval of about 6 weeks was taken before the start of orthodontic treatment. Regular orthodontic treatment was initiated by bonding both arches with a fixed orthodontic appliance to achieve initial leveling and alignment stage (OrthoPro MBT, 0.022'slot, Orthoprodent, USA). After the full completion of leveling and alignment; determined when an arch wire sized $0.017 \times 0.025$ inch St. St. could be inserted passively in the bracket slot, canine retraction was carried out in the control side directly on a mini-screw using closed coil spring (Figure 1). The retraction force was $150 \mathrm{~g}$ as measured using a force gauge (Coprex, Swiss made).

In Group A, 12 MOPs were made to a depth of $6 \mathrm{~mm}$; distributed as follows: Three buccally between the canine and lateral incisor roots and three between the canine root and the socket of the extracted premolar

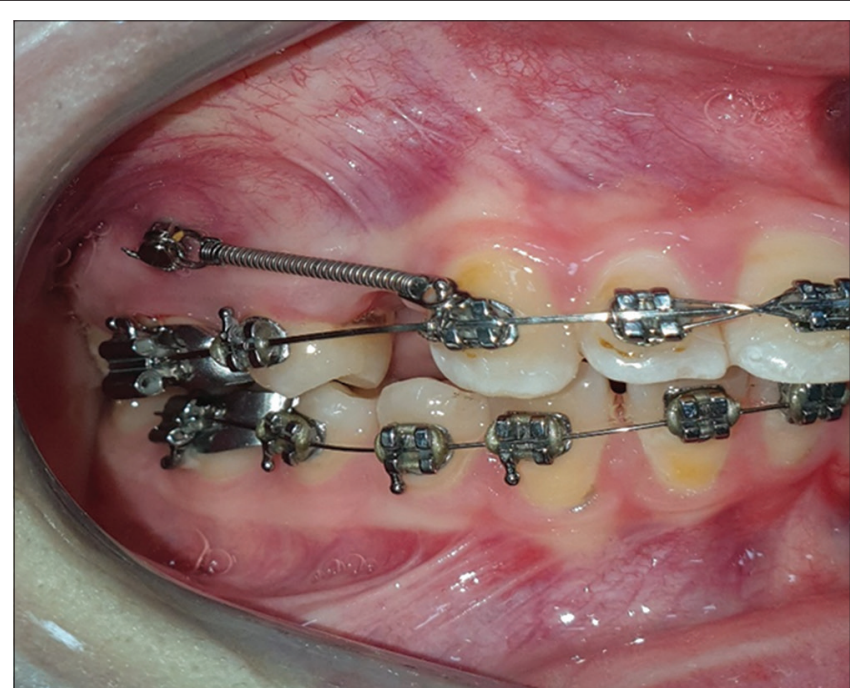

Figure 1: Retraction on the control side

(Figure 2). Further, three MOPs were made on the palatal side between the canine and lateral incisor roots and three between the canine root and the socket of the extracted premolar. This procedure was repeated every 2 weeks, such that MOPs were made 6 times over the 3 months study period. The mini-screws used to provide a perforation depth of $6 \mathrm{~mm}$ were $1.6 \mathrm{~mm}$ in diameter and $8 \mathrm{~mm}$ in length as the average gingival thickness is $2 \mathrm{~mm}$.

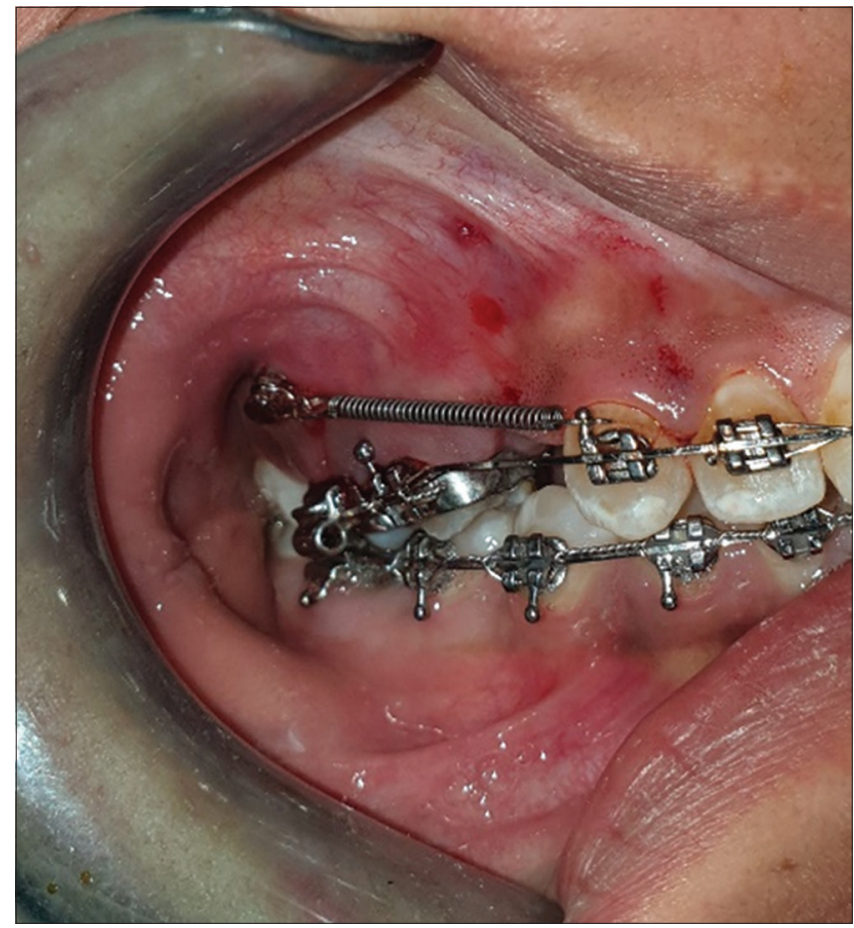

Figure 2: Micro-osteoperforations on the buccal side

In Group B using Piezotome and piezo surgical knife - BS 1insert and BP blade 15, two vertical interproximal piezocision cuts were placed (not including the free gingiva) on the mesio- and disto-buccal sides of the maxillary canines, piezocision cuts were performed $5 \mathrm{~mm}$ apical to the mesial and distal interdental papilla of the maxillary canines (Figure 3). Incision lengths were approximately $10 \mathrm{~mm}$ apically and the grooves in between the roots of the neighboring teeth were 
used as a guide for the cut lines. The incisions were made to a depth of $3 \mathrm{~mm}$ and a width of $3 \mathrm{~mm}$. The cuts were placed only on the buccal side under copious saline irrigation (sodium chloride $0.9 \% \mathrm{w} / \mathrm{v}$ ), then the area was sutured with an interrupted loop, non-resorbable Vicryl 4-0 black silk suture material. The sutures were left in place for 1 week and the patients were clinically checked every 2 weeks with a total of 5 times over 3 months. Data for the evaluation of each intervention were collected by direct intraoral measurements. The measurements were taken from the canine cusp tip to the mesiobuccal cusp tip of the maxillary 1st molar using digital intraoral caliper (IOS, China). Measurements were taken immediately before the beginning of canine retraction and every 2 weeks along the following 3 months.

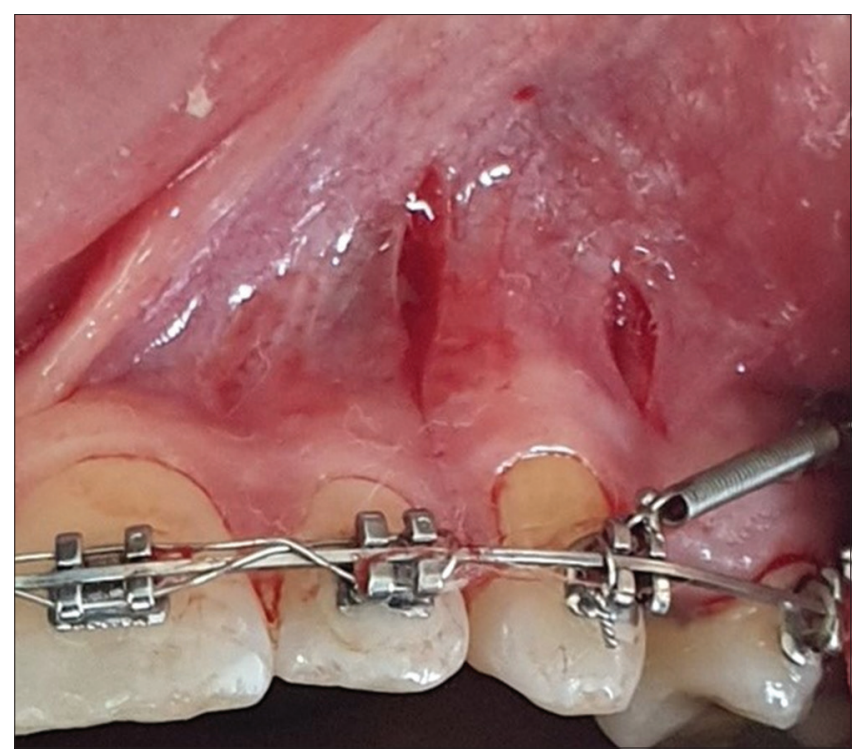

Figure 3: Piezocision cuts

The mean and standard deviation values were calculated for each group in each test. Data were explored for normality using Kolmogorov-Smirnov and Shapiro-Wilk tests and showed parametric (normal) distribution (split-mouth technique). Repeated measure ANOVA test was used to compare between more than 2 groups in related samples. Paired sample t-test was used to compare between two groups in related samples. Independent sample t-test was used to compare between two groups in non-related samples. The significance level was set at $p \leq 0.05$. Statistical analysis was performed with IBM尺 SPSS $®$ Statistics Version 20 for Windows.

\section{Results}

\section{first molar \\ Distance between canine tip and MB tip of \\ A. Relation between piezocision and \\ control}

The means and standard deviations for the piezocision group are shown in Table 1 and Figure 4.
Table 1: The mean and SD values of distance between canine tip and MB tip of first molar for the piezocision group (paired sample t-test)

\begin{tabular}{lllllll}
\hline Variables (weeks) & \multicolumn{5}{l}{ Distance between canine tip and MB tip of first molar } \\
\cline { 2 - 3 } & Piezocision & & & Control & & p-value \\
\cline { 2 - 3 } & Mean & SD & & Mean & SD & \\
\hline 0 & 20.52 & 1.00 & & 20.52 & 1.00 & $1 \mathrm{~ns}$ \\
2 & 19.44 & 1.04 & & 19.88 & 1.02 & $<0.001^{*}$ \\
4 & 18.66 & 1.04 & & 19.32 & 1.01 & $<0.001^{*}$ \\
6 & 18.05 & 1.09 & & 18.84 & 1.07 & $<0.001^{*}$ \\
8 & 17.67 & 1.06 & & 18.60 & 1.05 & $<0.001^{*}$ \\
10 & 17.26 & 1.09 & & 18.14 & 1.06 & $<0.001^{*}$ \\
12 & 16.93 & 1.09 & 17.76 & 1.02 & $<0.001^{*}$ \\
\hline${ }^{*}$ Significant $(p<0.05)$ ns: Non-significant ( $\left.p>0.05\right)$. SD: Standard deviation. & & &
\end{tabular}

\section{a. 0 week:}

There was no statistically significant difference between piezocision and control groups where $\mathrm{p}=1$.

b. 2 weeks:

There was a statistically significant difference between piezocision and control groups where $\mathrm{p}<0.001$

c. 4 weeks:

There was a statistically significant difference between piezocision and control groups where $\mathrm{p}<0.001$.

d. 6 weeks:

There was a statistically significant difference between piezocision and control groups where $p<0.001$.

e. $\quad 8$ weeks:

There was a statistically significant difference between piezocision and control groups where $p<0.001$.

f. $\quad 10$ weeks:

There was a statistically significant difference between piezocision and control groups where $\mathrm{p}<0.001$

g. 12 weeks:

There was a statistically significant difference between piezocision and control groups where $\mathrm{p}<0.001$.

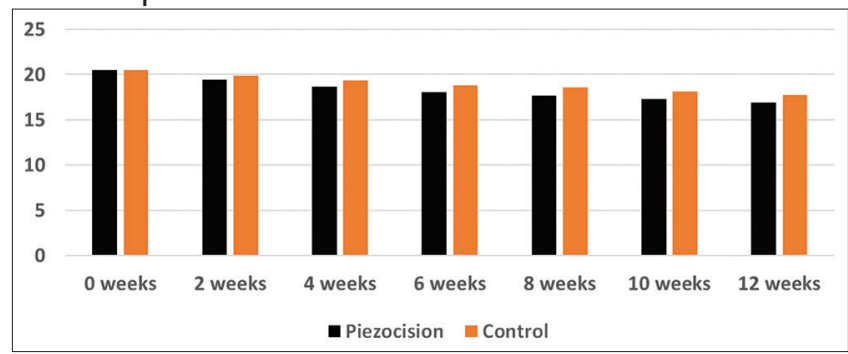

Figure 4: The mean distances between the canine tip and MB tip of the first molar in the piezocision group

\section{B. Relation between MOPs and control}

The means and standard deviations for the MOPs group are shown in Table 2 and Figure 5.

a. 0 week:

There was no statistically significant difference between MOPs and control groups where $p=1$. 
Table 2: The mean and SD values of distance between canine tip and MB tip of first molar for micro-osteoperforations group (paired sample t-test)

\begin{tabular}{|c|c|c|c|c|c|}
\hline \multirow[t]{3}{*}{ Variables (weeks) } & \multicolumn{5}{|c|}{ Distance between canine tip and MB tip of first molar } \\
\hline & \multicolumn{2}{|c|}{ Micro-osteoperforations } & \multicolumn{2}{|c|}{ Control } & \multirow[t]{2}{*}{$p$-value } \\
\hline & Mean & SD & Mean & SD & \\
\hline 0 & 20.47 & 1.04 & 20.47 & 1.04 & $1 \mathrm{~ns}$ \\
\hline 2 & 19.17 & 1.05 & 19.85 & 1.07 & $<0.001^{*}$ \\
\hline 4 & 18.35 & 1.02 & 19.16 & 1.12 & $<0.001^{*}$ \\
\hline 6 & 17.62 & 1.04 & 18.70 & 1.09 & $<0.001^{*}$ \\
\hline 8 & 17.17 & 1.00 & 18.52 & 1.13 & $<0.001^{*}$ \\
\hline 10 & 16.73 & 1.05 & 17.96 & 1.15 & $<0.001^{*}$ \\
\hline 12 & 16.30 & 1.08 & 17.64 & 1.08 & $<0.001^{*}$ \\
\hline
\end{tabular}

\section{b. 2 weeks:}

There was a statistically significant difference between MOPs and control groups where $p<$ 0.001 .

c. 4 weeks:

There was a statistically significant difference between MOPs and control groups where $p<$ 0.001 .

d. 6 weeks:

There was a statistically significant difference between MOPs and control groups where $p<$ 0.001 .

e. 8 weeks:

There was a statistically significant difference between MOPs and control groups where $p<$ 0.001 .

f. 10 weeks:

There was a statistically significant difference between MOPs and control groups where $p<$ 0.001 .

g. 12 weeks:

There was a statistically significant difference between MOPs and control groups where $p<$ 0.001 .

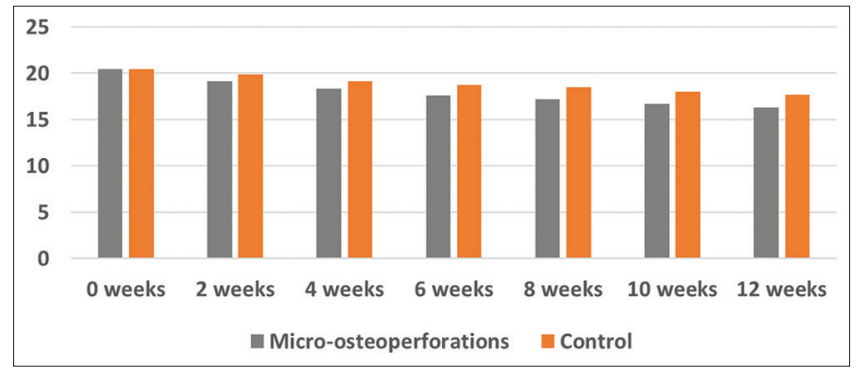

Figure 5: The mean distances between the canine tip and MB tip of the first molar in the micro-osteoperforations group

\section{MOPs}

\section{Relation between piezocision and}

The means and standard deviations for the piezocision and MOPs group are shown in Table 3 and Figure 6.

a. 0 week:

There was no statistically significant difference between piezocision and MOPs groups where $p=0.919$.
Table 3: The mean and SD values of distance between canine tip and MB tip of first molar (independent sample t-test) (repeated measure ANOVA)

\begin{tabular}{|c|c|c|c|c|c|}
\hline \multirow[t]{3}{*}{ Variables (weeks) } & \multicolumn{5}{|c|}{ Distance between canine tip and MB tip of first molar } \\
\hline & \multicolumn{2}{|c|}{ Piezocision } & \multicolumn{2}{|c|}{ Micro-osteoperforations } & \multirow[t]{2}{*}{$\mathrm{p}$-value } \\
\hline & Mean & SD & Mean & SD & \\
\hline 0 & 20.52 & 1.00 & 20.47 & 1.04 & $0.919 \mathrm{~ns}$ \\
\hline 2 & 19.44 & 1.04 & 19.17 & 1.05 & $0.578 \mathrm{~ns}$ \\
\hline 4 & 18.66 & 1.04 & 18.35 & 1.02 & $0.518 \mathrm{~ns}$ \\
\hline 6 & 18.05 & 1.09 & 17.62 & 1.04 & $0.386 \mathrm{~ns}$ \\
\hline 8 & 17.67 & 1.06 & 17.17 & 1.00 & $0.298 \mathrm{~ns}$ \\
\hline 10 & 17.26 & 1.09 & 16.73 & 1.05 & $0.287 \mathrm{~ns}$ \\
\hline 12 & 16.93 & 1.09 & 16.30 & 1.08 & $0.212 \mathrm{~ns}$ \\
\hline $\mathrm{p}$-value & $<0.001^{*}$ & & $<0.001^{*}$ & & \\
\hline
\end{tabular}

\section{b. 2 weeks:}

There was no statistically significant difference between piezocision and MOPs groups where $p=0.578$.

c. 4 weeks:

There was no statistically significant difference between piezocision and MOPs groups where $p=0.518$.

d. 6 weeks:

There was no statistically significant difference between piezocision and MOPs groups where $p=0.386$

e. 8 weeks:

There was no statistically significant difference between piezocision and MOPs groups where $p=0.298$.

f. 10 weeks:

There was no statistically significant difference between piezocision and MOPs groups where $\mathrm{p}=0.287$.

g. 12 weeks:

There was no statistically significant difference between piezocision and MOPs groups where $p=0.212$.

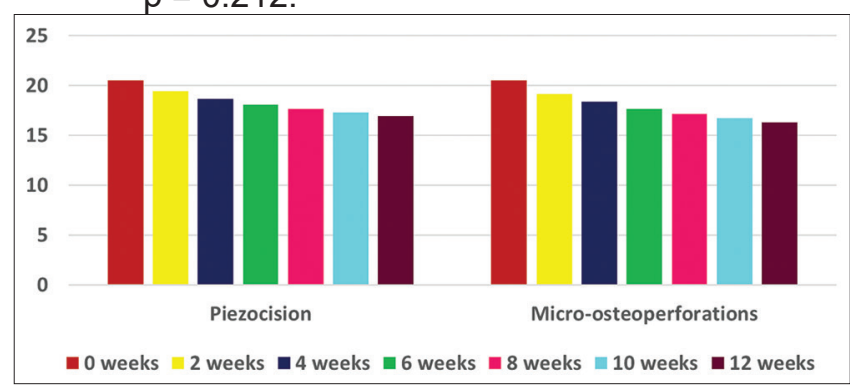

Figure 6: The mean distances between the canine tip and MB tip of the first molar both groups

\section{Relation between time periods}

\section{a. Piezocision}

There was a statistically significant difference between 0 week, 2 weeks, 4 weeks, 6 weeks, 8 weeks, 10 weeks, and 12 weeks groups where $p<0.001$.

A statistically significant difference between 0 weeks and each of 2 weeks, 4 weeks, 6 weeks, 8 weeks, 10 weeks, and 12 weeks groups where $p<0.001$.

Furthermore, a statistically significant difference was found between 2 weeks and each of 4 weeks, 6 weeks, 8 weeks, 10 weeks, and 12 weeks 
groups where $\mathrm{p}<0.001$.

A statistically significant difference was found between 4 weeks and each of 6 weeks, 8 weeks, 10 weeks, and 12 weeks groups where $p<0.001$.

Furthermore, a statistically significant difference was found between 6 weeks and each of 8 weeks, 10 weeks, and 12 weeks groups where $p<0.001$.

A statistically significant difference was found between 8 weeks and each of 10 weeks and 12 weeks groups where $p<0.001$.

A statistically significant difference was found between 10 weeks and 12 weeks groups where $p<0.001$.

\section{b. MOPs}

There was a statistically significant difference between 0 week, 2 weeks, 4 weeks, 6 weeks, 8 weeks, 10 weeks, and 12 weeks groups where $p<0.001$.

A statistically significant difference between 0 week and each of 2 weeks, 4 weeks, 6 weeks, 8 weeks, 10 weeks, and 12 weeks groups where $p<0.001$

Furthermore, a statistically significant difference was found between 2 weeks and each of 4 weeks, 6 weeks, 8 weeks, 10 weeks, and 12 weeks groups where $p<0.001$.

A statistically significant difference was found between 4 weeks and each of 6 weeks, 8 weeks, 10 weeks, and 12 weeks groups where $p<0.001$.

Furthermore, a statistically significant difference was found between 6 weeks and each of 8 weeks, 10 weeks, and 12 weeks groups where $p<0.001$.

A statistically significant difference was found between 8 weeks and each of 10 weeks and 12 weeks groups where $p<0.001$.

A statistically significant difference was found between 10 weeks and 12 weeks groups where $p<0.001$.

\section{Discussion}

In an era of speed and high competition, decreasing the duration of orthodontic treatment is turning to be a must. MOPs and piezoelectric surgery (piezocision) are new emerging methods for accelerating orthodontic tooth movement yet under investigation by many researchers [30], [31]. Many approaches were presented for canine retraction into the extraction space; discussing anchorage preparation and the magnitude of the used retraction force (magnitude, direction, and force decay) [32], [33]. [34]. Aboul-Ela et al. [24] stated that titanium mini-screws provided an easy and effective skeletal anchorage for canine retraction. In the current study, direct anchorage using mini-screws between the $2^{\text {nd }}$ premolars and $1^{\text {st }}$ permanent molars, during canine retraction on a closed coil spring, was selected. This set up eliminates any anchorage loss from the molars which may result in confusing false results during measurements. The chosen force magnitude was $150 \mathrm{~g}$ adopted from Barlow and Kula [35] who concluded, in their systematic review, that there was no added advantage in the $200 \mathrm{~g}$ force over the $150 \mathrm{~g}$ force magnitude concerning the rate of canine retraction. The statistical analysis of the direct intraoral measurements for Group A (MOPs group) showed a significantly higher rate of canine retraction in the study side. This was in agreement with the trial carried out by Alikhani et al. [36] who found a 2-3-fold rise in the rate of orthodontic tooth movement with MOPs. When this method was experimented on rats, it was observed to be effective in enhancing the rate of tooth movement [37]. Further, investigations on rats by Tsai et al. revealed similar results [38]. In this study, the rate of canine retraction in the MOPs side was higher by nearly 1.5 -fold compared to canine retraction in the control side over the 3 months period. The highest rate was observed during the first 4 weeks, measuring nearly $0.9 \mathrm{~mm}$ every 2 weeks, that was in agreement with other clinical trials and is explained by the accelerator effect that accompanies the MOPs procedure which is at its maximum in the $1^{\text {st }}$ month [22], [26]. Wilcko et al. [16] theorized that the rapid orthodontic canine retraction and minimal apical root resorption that accompanied periodontal accelerated osteogenic orthodontics were attributable to increased regional bone turn over (the RAP) and the associated osteopenia, that is, calcium depletion and diminished bone density, precipitated by selective decortication. They further explained that the dynamics of the physiologic tooth movement in these patients might be more appropriately described as bone matrix transportation. In addition, the rate of tooth movement is controlled by osteoclast recruitment and activation [21]. Therefore, regardless of the shape or the extent of the cut; bone resorption will not occur unless osteoclasts are activated. This means that similar to MOPs, the effectiveness of corticotomy [25] or piezocision [39] can be related to the activation of cytokines that are released in response to the trauma induced during the cuts [40].

Similarly, Group B showed a significantly higher rate of canine retraction in the study side that was in agreement with other studies [19], [28]. The rate of canine retraction in the piezocision side was higher by nearly 1.3-fold compared to standard canine retraction over the 3 months period. The ability of piezocision to accelerate canine retraction can be also explained by the RAP as with the MOPs. On reviewing the literature, piezocision cuts were placed vertically close to the canine to be retracted and as far as possible from the 
anchor teeth [41] such that the longer and the deeper the incision, the more the effect of the RAP [20].

On the other hand, there was no statistically significant difference between piezocision and MOPs groups. Nevertheless, the MOPs group was 0.2-fold faster than the piezocision group.

Within the limitations of this study, it can be deducted that the adjunctive use of either MOPs or piezocision with orthodontic treatment could be clinically worthwhile; with MOPs being slightly more effective over piezocision.

\section{Conclusion}

- $\quad$ MOPs and piezocision techniques accelerated the rate of canine retraction during orthodontic treatment

- $\quad$ MOPs technique provided a slightly greater acceleration than piezocision.

\section{Research ethical approval}

This study was made with the approval of the Ethical Committee of the Faculty of Dentistry, Minia University.

\section{References}

1. Fisher MA, Wenger RM, Hans MG. Pretreatment characteristics associated with orthodontic treatment duration. Am J Orthod Dentofac Orthop. 2010;137(2):178-86. https://doi.org/10.1016/j. ajodo.2008.09.028

PMid:20152672

2. Pandis N, Nasika M, Polychronopoulou A, Eliades T. External apical root resorption in patients treated with conventional and self-ligating brackets. Am J Orthod Dentofac Orthop. 2008;134(5):646-51. https://doi.org/10.1016/j. ajodo.2007.01.032

PMid:18984396

3. Bishara SE, Ostby AW. White spot lesions: Formation, prevention, and treatment. Semin Orthod. 2008;14(3):174-82. https://doi.org/10.1053/j.sodo.2008.03.002

4. Roykó A, Dénes Z, Razouk G. The relationship between the length of orthodontic treatment and patient compliance. Fogorv Sz. 1999;92(3):79-86.

PMid:10205984

5. Gkantidis N, Mistakidis I, Kouskoura T, Pandis N. Effectiveness of non-conventional methods for accelerated orthodontic tooth movement: A systematic review and meta-analysis. J Dent. 2014;42(10):1300-19. https://doi.org/10.1016/j. jdent.2014.07.013

PMid:25072362

6. Blanco JF, Diaz R, Gross HR. Effect of systemic administration of 1,25 di-hydroxy colecalciferol on acceleration of orthodontic tooth movement in humans. Rev Orthod. 2001;8:13-21.

7. Patil AK, Keluskar KM, Gaitonde SD. The clinical application of prostaglandin E1 on orthodontic tooth movement-a clinical trial. J Indian Orthod Soc. 2005;39(2):91-8. https://doi. org/10.1177/0974909820050204

8. Hou Y, Liang T, Luo C. Effects of IL-1 on experimental tooth movement in rabbits. Zhonghua Kou Qiang Yi Xue Za Zhi. 1997;32(1):46-8.

PMid:10677947

9. Mohammed AH, Tatakis DN, Dziak R. Leukotrienes in orthodontic tooth movement.Am JOrthod DentofacOrthop. 1989;95(3):231-7. https://doi.org/10.1016/0889-5406(89)90053-x PMid:2538053

10. Rashid A, EISharaby FA, Nassef EM, Mehanni S, Mostafa YA Effect of platelet-rich plasma on orthodontic tooth movement in dogs. Orthod Craniofac Res. 2017;20(2):102-10. https://doi. org/10.1111/ocr.12146

PMid:28414871

11. Shirazi M, Ahmad Akhoundi MS, Javadi E, Kamali A, Motahhari $P$, Rashidpour M, et al. The effects of diode laser $(660 \mathrm{~nm})$ on the rate of tooth movements: An animal study. Lasers Med Sci. 2015;30(2):713-8. https://doi.org/10.1007/s10103-013-1407-1 PMid:23917413

12. Kim DH, Park YG, Kang SG. The effects of electrical current from a micro-electrical device on tooth movement. Korean J Orthod. 2008;38(5):337. https://doi.org/10.4041/kjod.2008.38.5.337

13. Showkatbakhsh $R$, Jamilian A, Showkatbakhsh M. The effect of pulsed electromagnetic fields on the acceleration of tooth movement. World J Orthod. 2010;11(4):e52-6.

PMid:21490989

14. Xue H, Zheng J, Cui Z, Bai X, Li G, Zhang C, et al. Low-intensity pulsed ultrasound accelerates tooth movement via activation of the BMP-2 signaling pathway. PLoS One. 2013;8(7):e68926. https://doi.org/10.1371/journal.pone.0068926 PMid:23894376

15. Abed S, Abed SS,Al-BustaniAl. Corticotomy assisted orthodontic canine retraction. J Baghdad Coll Dent. 2014;25:160-6. Available from: https://www.jbcd.uobaghdad.edu.iq/index.php/ jbcd/article/view/217. [Last accessed on 2021 May 06]. https:// doi.org/10.12816/0015134

16. Wilcko W, Wilcko MT. Accelerating tooth movement: The case for corticotomy-induced orthodontics. Am J Orthod Dentofac Orthop. 2013;144(1):4-12. https://doi.org/10.1016/j. ajodo.2013.04.009

PMid:23810038

17. Alikhani M, Alansari S, Sangsuwon C, Alikhani M, Chou MY, Alyami B, et al. Micro-osteoperforations: Minimally invasive accelerated tooth movement. Semin Orthod. 2015;21(3):162-9. https://doi.org/10.1053/j.sodo.2015.06.002

18. Alkebsi A, Al-Maaitah E, Al-Shorman H, Abu Alhaija E. Threedimensional assessment of the effect of micro-osteoperforations on the rate of tooth movement during canine retraction in adults with Class II malocclusion: A randomized controlled clinical trial. Am J Orthod Dentofac Orthop. 2018;153(6):771-85. https://doi. org/10.1016/j.ajodo.2017.11.026 PMid:29853235

19. Abbas NH, Sabet NE, Hassan IT. Evaluation of corticotomyfacilitated orthodontics and piezocision in rapid canine retraction. Am J Orthod Dentofacial Orthop. 2016;149(4):473-80. https:// doi.org/10.1016/j.ajodo.2015.09.029 PMid:27021451

20. Yi J, Xiao J, Li Y, Li X, Zhao Z. Efficacy of piezocision on accelerating orthodontic tooth movement: A systematic review. Angle Orthod. 2017;87(4):491-8. https://doi. org/10.2319/01191-751.1 


\section{PMid:28429956}

21. Cano J, Campo J, Bonilla E, Colmenero C. Corticotomyassisted orthodontics. J Clin Exp Dent. 2012;4(1):54-9. https:// doi.org/10.4317/jced.50642

PMid:24558526

22. Wang L, Lee W, Lei DL, Liu YP, Yamashita DD, Yen SL. Tissue responses in corticotomy and osteotomy-assisted tooth movement in the rat. Int J Oral Maxillofac Surg. 2009;38(5):473. https://doi.org/10.1016/j.ijom.2009.03.273

23. Mostafa YA, Fayed MM, Mehanni S, EIBokle NN, Heider AM. Comparison of corticotomy-facilitated vs standard toothmovement techniques in dogs with miniscrews as anchor units. Am J Orthod Dentofac Orthop. 2009;136(4):570-7. https://doi. org/10.1016/j.ajodo.2007.10.052

PMid:19815161

24. Aboul-Ela SM, El-Beialy AR, El-Sayed KM, Selim EM, El-Mangoury NH, Mostafa YA. Miniscrew implant-supported maxillary canine retraction with and without corticotomy-facilitated orthodontics. Am J Orthod Dentofac Orthop. 2011;139(2):252-9. https://doi.org/10.1016/j.ajodo.2009.04.028 PMid:21300255

25. Al-Naoum F, Hajeer MY, Al-Jundi A. Does alveolar corticotomy accelerate orthodontic tooth movement when retracting upper canines? A split-mouth design randomized controlled trial. J Oral Maxillofac Surg. 2014;72(10):1880-9. https://doi.org/10.1016/j. joms.2014.05.003 PMid:25128922

26. Cassetta M, Di Carlo S, Giansanti M, Pompa V, Pompa G, Barbato $\mathrm{E}$. The impact of osteotomy technique for corticotomyassisted orthodontic treatment (CAOT) on oral health-related quality of life. Eur Rev Med Pharmacol Sci. 2012;16(12):1735-40. PMid:23161049

27. Sangsuwon C, Alansari S, Nervina J, Teixeira CC, Alikhani M. Micro-osteoperforations in accelerated orthodontics. Clin Dent Rev. 2018;2(1):1-10. https://doi.org/10.1007/ s41894-017-0013-1

28. Abbas IT, Moutamed GM. Acceleration of orthodontic tooth movement by alveolar corticotomy using piezosurgery. J Am Sci. 2012;2(1545-1003):13-9. Available from: http://www.jofamericanscience.org/journals/am-sci/ am0802/003_7870am0802_13_19.pdf. [Last accessed on 2021 Jan 30].

29. Mostafa YA, El-mangoury NH, Abouelezz A. Maximizing tissue response in selected subjects with anterior open bite. World $\mathrm{J}$ Orthod. 2009;10(3):187-795.

PMid:19885419

30. Shahabee $M$, Shafaee $H$, Abtahi M, Rangrazi A, Bardideh $E$. Effect of micro-osteoperforation on the rate of orthodontic tooth movement-a systematic review and a meta-analysis. Eur $\mathrm{J}$ Orthod. 2020;42(2):211-21. https://doi.org/10.1093/ejo/cjz049 PMid:31215993

31. Fu T, Liu S, Zhao H, Cao M, Zhang R. Effectiveness and safety of minimally invasive orthodontic tooth movement acceleration: A systematic review and metaanalysis. J Dent Res. 2019;98(13):1469-79. https://doi. org/10.1177/0022034519878412

\section{PMid:31589824}

32. Keng FY, Quick AN, Swain MV, Herbison P. A comparison of space closure rates between preactivated nickel-titanium and titanium-molybdenum alloy T-loops: A randomized controlled clinical trial. Eur J Orthod. 2012;34(1):33-38. https://doi. org/10.1093/ejo/cjq156

PMid:21415288

33. Kulshrestha RS, Tandon R, Chandra P. Canine retraction: A systematic review of different methods used. J Orthod Sci. 2015;4(1):1-8. https://doi.org/10.4103/2278-0203.149608 PMid:25657985

34. Mohammed H, Rizk MZ, Wafaie K, Almuzian M. Effectiveness of nickel-titanium springs vs elastomeric chains in orthodontic space closure: A systematic review and meta-analysis. Orthod Craniofac Res. 2018;21(1):12-19. https://doi.org/10.1111/ ocr. 12210

\section{PMid:29265578}

35. Barlow M, Kula K. Factors influencing efficiency of sliding mechanics to close extraction space: A systematic review. Orthod Craniofac Res. 2008;11(2):65-73. https://doi. org/10.1111/j.1601-6343.2008.00421.x

PMid:18416747

36. Alikhani M, Raptis M, Zoldan B, Sangsuwon C, Lee YB, Alyami $B$, et al. Effect of micro-osteoperforations on the rate of tooth movement. Am J Orthod Dentofac Orthop. 2013;144(5):639-48. https://doi.org/10.1016/j.ajodo.2013.06.017 PMid:24182579

37. Teixeira CC, Khoo E, Tran J, Chartres I, Liu Y, Thant LM, et al. Cytokine expression and accelerated tooth movement. J Dent Res. 2010;89(10):1135-41.

PMid:20639508

38. Tsai CY, Yang TK, Hsieh HY, Yang LY. Comparison of the effects of micro-osteoperforation and corticision on the rate of orthodontic tooth movement in rats. Angle Orthod. 2016;86(4):558-64. https://doi.org/10.2319/052015-343.1 PMid:26595657

39. Figueiredo DS, Houara RG, Pinto LS, Diniz AR, de Araújo VE, Thabane $L$, et al. Effects of piezocision in orthodontic tooth movement: A systematic review of comparative studies. J Clin Exp Dent. 2019;11(11):e1078-92. https://doi.org/10.4317/ jced. 56328 PMid:31700581

40. Murphy KG, Wilcko MT, Wilcko WM, Ferguson DJ. Periodontal accelerated osteogenic orthodontics: A description of the surgical technique. J Oral Maxillofac Surg. 2009;67(10):2160-6. https://doi.org/10.1016/j.joms.2009.04.124 PMid:19761909

41. Al-Imam GM, Ajaj MA, Hajeer MY, Al-Mdalal Y, Almashaal E. Evaluation of the effectiveness of piezocision-assisted flapless corticotomy in the retraction of four upper incisors: A randomized controlled clinical trial. Dent Med Probl. 2019;56(4):385-394. https://doi.org/10.17219/dmp/110432

PMid:31794163 